\title{
Longitudinal effects in geomagnetic disturbances at mid-latitudes
}

\author{
R. G. Rastogi ${ }^{1,2}$, D. E. Winch ${ }^{2}$, and M. E. James ${ }^{1}$ \\ ${ }^{1}$ Department of Physics, Gujarat University, Ahmedabad, 380009, India \\ ${ }^{2}$ Department of Mathematics and Statistics, University of Sydney, NSW 2006, Australia
}

(Received January 15, 2001; Revised August 14, 2001; Accepted August 14, 2001)

\begin{abstract}
The paper describes the differences in the magnetic disturbance effect on horizontal geomagnetic field $(H)$ and declination $(D)$ at Alibag (India), Lunping (Taiwan), Chichijima (Japan) and Kakioka (Japan). It is suggested that the trapped particles in the earth's magnetic field lines are guided by the dipole declination and not by the ground declination and follow the direction towards the geomagnetic pole. The disturbance vector is given by $\sin (\psi-D)$ where $\psi$ and $D$ are dipole and ground declinations of the station respectively. The mean disturbance daily variation $(S D)$ of $H$ field is similar at all stations but $S D$ of eastward field $(Y)$ is negative at Alibag but positive at Lunping, Chichijima and Kakioka. Similarly, the daily mean values of $H$ field systematically decrease with increasing ring current index (decreasing value of $D s t$ index) for all stations. But declination values are positively related with Dst index at Alibag and negatively related at Lumping, Chichijima and Kakioka. The SSC amplitude in $Y$ field shows negative values at Alibag but positive values at Kakioka. The storm-time variations $\operatorname{Dst}(H)$ show negative excursion during the main phase of the storm at Alibag, Lunping, Chichijima and Kakioka. On the other hand, the Dst variations in declination during the main phase show negative excursions at Alibag but positive excursions at Lumping and Chichijima. This shows a very significant longitudinal inequality in storm-time behavior of eastward geomagnetic field at any place on the earth.
\end{abstract}

\section{Introduction}

A classical geomagnetic observatory operates on a continuous basis, and records the three components of the earth's magnetic field (i) the horizontal field $H$ (ii) the vertical field $Z$, considered positive when pointing downwards and (iii) declination $D$, representing the deviation of the direction of $H$ from the geographic meridian. The angle $D$ is considered positive (or easterly) when $H$ field points eastward of the geographic north, and is negative (or westerly) when $H$ field points westward of the geographic north. The $H$ and $Z$ fields are expressed in units of nano-Tesla (nT) while $D$ is expressed in degrees and minutes of arc. The $H$ and $D$ components of geomagnetic field can be converted into northward $(X)$ and eastward $(Y)$ components by simple trigonometric equations.

$$
\text { Eastward field } Y(\mathrm{nT})=H(\mathrm{nT}) * \sin D .
$$

By differentiating the above equation we get

$$
\Delta Y(\mathrm{nT})=H(\mathrm{nT}) * \operatorname{Cos} D * \Delta D+\Delta H * \sin D .
$$

At equatorial latitudes, $H$ is of the order of a few $10^{4} \mathrm{nT}$ and $\Delta H$ is of the order of a few tens of nT, $D$ is of the order of a few degrees and $\Delta D$ is only a few minutes of arc. If $D$ and $\Delta D$ are expressed in radians, then $\operatorname{Cos} D$ is close to unity and $\operatorname{Sin} D$ is close to zero. Then the above equation

Copy right (C) The Society of Geomagnetism and Earth, Planetary and Space Sciences (SGEPSS); The Seismological Society of Japan; The Volcanological Society of Japan; The Geodetic Society of Japan; The Japanese Society for Planetary Sciences. reduces to

$$
\begin{aligned}
\Delta Y(\mathrm{nT}) & =H(\mathrm{nT}) * \Delta D(\text { radian }) \\
& =H(\mathrm{nT}) * \Delta D(\text { minutes of arc }) / 3438
\end{aligned}
$$

there being 3438 minutes of arc in one radian.

At equatorial and low latitudes, the predominance of solar daily variation of $H$ field prompted scientists to give more attention towards the studies of daily variation of $H$ field. It is also to be noted that the magnetometers have comparatively low sensitivities for $D$ as compared to that for $H$, further reduced the importance of $D$ recordings. Rastogi (1993a) showed that the declination at Kodaikanal has remarkable regular daily, seasonal and solar cycle variations similar to $H$ field and the two components are closely associated with each other. The studies of solar flare effects in $H$ and $D$ components at low latitude stations by Rastogi (1996a, 1999a) and Rastogi et al. (1999) have shown that the direction of magnetic field vectors on the horizontal plane due to solar flare remains practically the same as that of the pre-flare quiet-day solar daily variation vector $(S q)$. Thus, the meridional current during the flare producing the change of $D$ flows in the same region of the ionosphere as the zonal current producing the change of $H$ field.

Moos (1910) analyzed the data of the geomagnetic observatory at Colaba, India for an extended period 1846 to 1905. He identified well defined pattern in the so called " $X$ disturbance" in the geomagnetic horizontal field $(H)$, characterized by a sudden initial rise followed by a rapid decrease lasting a few hours and a slow recovery lasting 2 to 3 days. Chapman (1918) defined these disturbances as "ge- 
omagnetic storms" and the various phases of disturbance as sudden storm commencement (SSC), initial, main and recovery phase.

Schmidt (1917) ascribed the decrease of $H$ field during the main phase of geomagnetic storms to the effect of a westward current encircling the earth. Chapman and Ferraro (1931a, b, 1932a, b) suggested that geomagnetic storms are due to the impact on the earth of a ionized solar plasma bubble ejected from the sun. The decrease of $H$ during main phase was suggested as due to the penetration of some of the plasma within the influence of the geomagnetic field forming a ring current around the earth. Singer (1957) suggested that the charged particle from the sun after penetrating earth's geomagnetic field oscillate rapidly to and fro along the earth's magnetic field between the mirror points in fairly high northern and southern latitudes. Due to nonuniformity of earth's magnetic field along the path these particles drift around the earth, the protons moving westward and electrons eastward. These motions correspond to a westward equatorial ring current around the earth. Akasofu and Chapman (1961) evaluated the effects of a model radiation belt on the ring current and the geomagnetic disturbance. They suggested that, only axially aligned horizontal field needs to be used to define the world-wide storm-time effects. To derive the longitudinal symmetric and asymmetric components in $H$ and $Y$ fields during magnetic storm periods, Iyemori (1990) considered that the ring current flows parallel to the dipole equatorial plane. Since the realization of a continuous solar wind, the ring current is assumed to be present at all times, varying intensity depending on the storminess of the geomagnetic field. This cause the $H$ field at any place on the earth to be decreased on geomagnetically disturbed days compared to quiet days. Sugiura (1964) standardized the procedure to derive the hourly means of $D s t$ index for each day using the $H$ data from eight well distributed low latitude observatories, which are not seriously affected by the currents in the ionosphere like the equatorial and auroral electrojet currents. The Dst index represents the strength of westward equatorial ring current at about 4 6 earth radii. Generally Dst index is negative and decreases (becomes more negative) with increasing storminess.

The geomagnetic disturbance effects at any particular station include variations related to both universal time and local solar time. The mean daily variations of geomagnetic field component on international quiet (IQ) days of the month and international disturbed (ID) days of the month are represented by $S q$ and $S d$ respectively, and then $S d-S q$ designates the additional daily variations due to disturbances. It is called Disturbance Daily variations and is denoted as $S D$. In case of individual magnetic storm, the first impulse in magnetogram is indicative of SSC and is generally positive in the $H$ field. The SSC effects in declination seemed to be absent (Akasofu, 1961). Subtracting the $S q$ variations from the geomagnetic field components on three days following the SSC and arranging these $S d-S q$ values with UT beginning with the hours of SSC gives the storm-time variations of the components at the stations, denoted as $\operatorname{Dst}(H)$ and $\operatorname{Dst}(Y)$ variations. Vestine et al. (1947) studied the $S q$ and $S d$ variations of $X, Y$ and $Z$ fields at a number of stations. Obayashi and Jacobs (1957) studied the global mor- phology of SSC in the three components of the geomagnetic field, and identified an extra-terrestrial as well as an ionospheric component in the SSC. Simultaneous changes in $D$ and $H$ fields during a SSC were examined by Wilson and Sugiura (1961) and by Sano (1963) from the rapid run magnetograms taken during the IGY. Tsunomura (1998) has studied the characteristics of SSC in $H$ and $D$ components of the geomagnetic field at a number of middle and low latitude stations. He identified a negative impulse of SSC in $H$ field superposed on the main impulse of SSC in $H$ field just after its onset during daytime hours. He suggested this negative impulse as due to the polar originated ionospheric current system.

Rastogi (1992) showed that the declination (westerly) at Kodaikanal were consistently larger through out the day on ID days than on IQ days for all the years 1956 to 1960 . He found that the storm-time variations of $D(w)$ and $H$ fields were remarkably similar to each other for the stations Kodaikanal and Alibag. Further, the daily mean values of $D$ and $H$ fields at Kodaikanal decreased steadily with decreasing value of $\operatorname{Dst}(H)$ index. Similar features of the $S D$ and $D s t$ variations of $Y$ and $H$ fields were found at Huancayo, a station in American sector (Rastogi, 1993b). Tsunomura et al. (1999) has described a comprehensive study of geomagnetic storms in $H, D$ and $Z$ components of the field at a chain of Japanese observatories. They identified diurnal variation patterns in the $H$ and $D$ components during storm time.

Fukushima (personal communication) strongly recommended a detailed study of the quiet and disturbed variations of declination at different stations around the world. It was realized that if the disturbance effects at ground are due to the disturbance equatorial ring current, then the direction of the ring current should be normal to the geomagnetic field lines at 4-6 earth radii. This suggests that the disturbance effects in declination should have a geomagnetic longitudinal variation. The present study describes the results of such an enquiry. The data at Alibag (India) and at Kakioka (Japan) for IGY period and Lunping (Taiwan) and Chichijima (Japan) for the year 1991 have been analyzed. The coordinates and some other relevant parameters for these stations are given in Table 1. The station Alibag is west of $180^{\circ}$ geomagnetic meridian and hence the plane of ring current particle oscillations would be tilted west of geographic meridian. The stations Lumping, Chichijima and Kakioka are located east of the $180^{\circ}$ geomagnetic meridian and hence the plane of oscillations of the particles would be tilted eastward of the geographic meridian.

\section{The Plane of Trapped Charged Particles in the Magnetosphere}

It is assumed that the motion of charged particles at the altitudes of ring current in the magnetosphere follow dipole lines of force. Thus, the direction of magnetic field due to the ring current over a particular station should be given by angle $\psi$ (dipole declination) from the geographical north and pointing towards the geomagnetic pole. In other words, the ring current flows on the equatorial plane in dipole coordinate system. The declination measurements at the ground (D) are made with respect to geographic north. Thus, any 


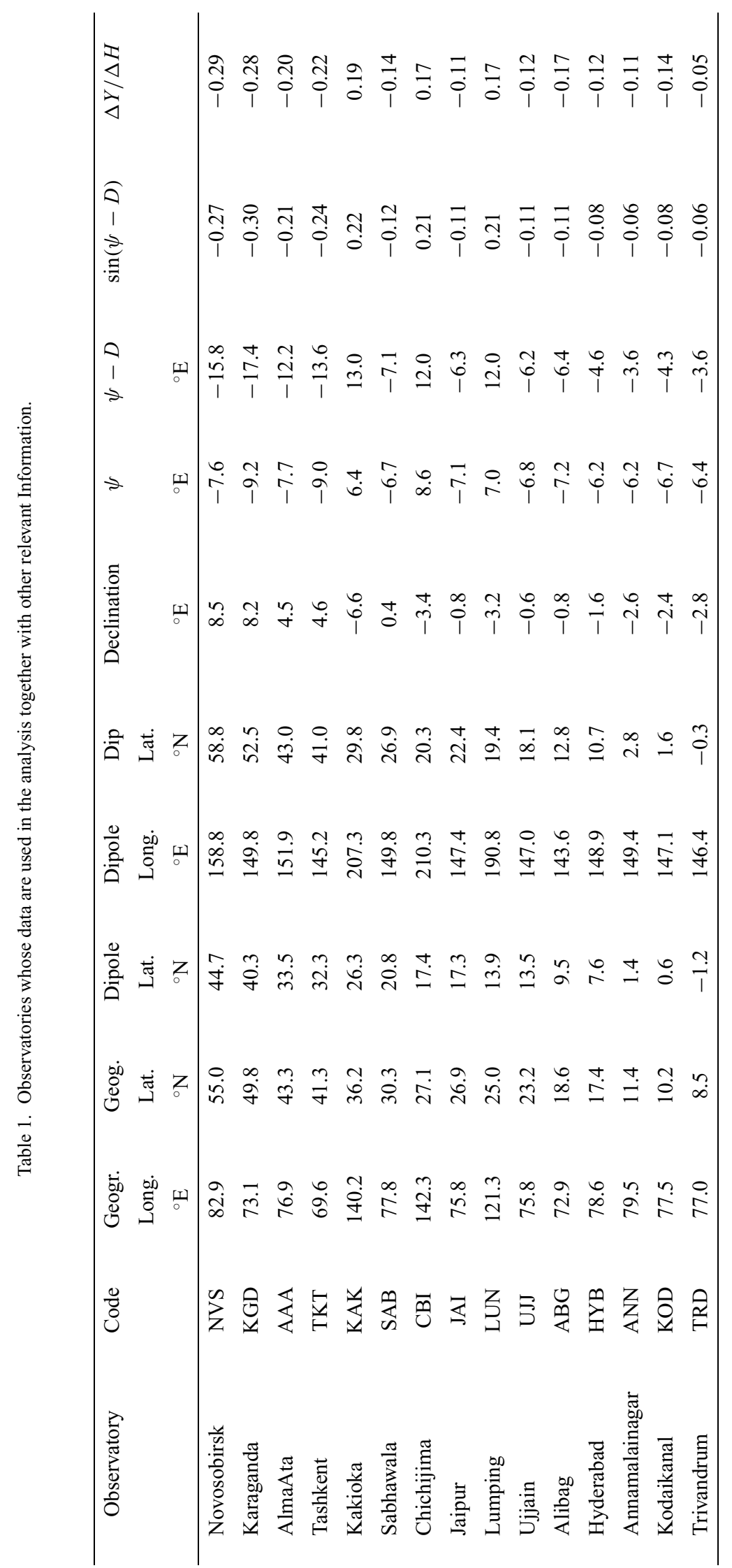




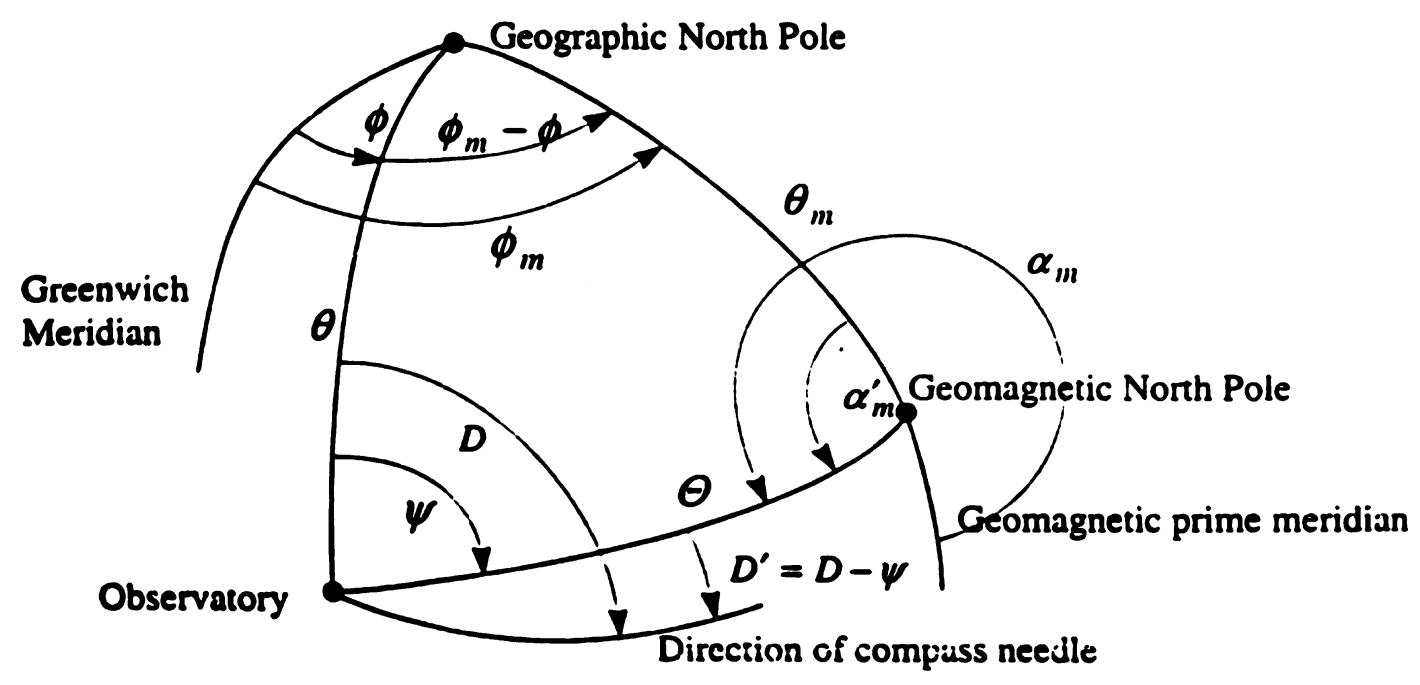

Fig. 1. The positions of the north geographic and geomagnetic poles with respect to the geographic, magnetic (ground) and dipole meridians over the observatory.

deviation of declination due to ring current should be related to the angel between the dipole declination and the ground declination $(D)$. If we assume simultaneous changes in $\Delta Y$ and $\Delta H$ to be small during the magnetic disturbance then $\Delta Y / \Delta H$ should follow $\sin (\psi-D)$. The angle $\psi$ can be calculated as follows.

The spherical geometry of the geographic meridian, geomagnetic prime meridian and ground magnetic meridians together with various angles are shown in Fig. 1. Here, $\theta$ is the geographic co-latitude and $\phi$ is the geographic longitude (with respect to the Greenwich meridian) of the geomagnetic observatory. The co-latitude $\theta_{m}$ and east longitude $\phi_{m}$ of the geomagnetic dipole axis is to be obtained first. Using International Geomagnetic Reference Field (IGRF) for 1985, the first order spherical harmonic coefficients are

$$
\begin{aligned}
& g_{0}^{1}=-29874.2=M \cos \theta_{m}^{\prime} \\
& g_{1}^{1}=-1904.5=M \sin \theta_{m}^{\prime} \cos \phi_{m}^{\prime} \\
& h_{1}^{1}=5496.4=M \sin \theta_{m}^{\prime} \sin \phi_{m}^{\prime}
\end{aligned}
$$

where $M$ is the dipole strength. Of course, from this calculation one finds the coordinates of the south geomagnetic pole $\left(\theta_{m}^{\prime}, \phi_{m}^{\prime}\right)$, and

$$
\begin{aligned}
M= & 30435 \\
\theta_{m}^{\prime}= & 168.981^{\circ} \text { (co-latitude) } \\
& 78.981^{\circ} \mathrm{S} \text { (geographic latitude) } \\
\phi_{m}^{\prime}= & 109.117^{\circ} \text { (east longitude) }
\end{aligned}
$$

$19.117^{\circ} \mathrm{E}$ (geographic longitude).

The corresponding co-ordinates $\left(\theta_{m}, \phi_{m}\right)$ of the north geomagnetic dipole are

$$
\begin{aligned}
\theta_{m}= & 11.019^{\circ}(\text { co-latitude }) \\
& 78.981^{\circ} \mathrm{N}(\text { geographic latitude }) \\
\phi_{m}= & 289.111^{\circ}(\text { east longitude }) \\
& 70.889^{\circ} \mathrm{W} \text { (geographic longitude } .
\end{aligned}
$$

The geomagnetic co-latitude $(\emptyset)$ of the observatory is then obtained from the cosine rule as

$$
\cos \emptyset=\cos \theta \cos \theta_{m}+\sin \theta \sin \theta_{m} \cos \left(\phi_{m}-\phi\right) .
$$

The angle $\psi$ between the geographic and geomagnetic meridians is given in its correct quadrant by the sine and the four-part rules

$$
\begin{aligned}
\sin \psi & =\frac{\sin \left(\phi_{m}-\phi\right) \sin \theta_{m}}{\sin \emptyset} \\
\cos \psi & =\frac{\cos \theta_{m} \sin \theta-\sin \theta_{m} \cos \theta \cos \left(\phi_{m}-\phi\right)}{\sin \emptyset} .
\end{aligned}
$$

Taking an example of Alibag, where

$$
\begin{aligned}
\text { Co-latitude } \theta= & 71.383^{\circ} \\
\text { Longitude } \phi= & 72.867^{\circ} \mathrm{E} \\
\phi_{m}-\phi= & 216.244^{\circ} \\
\varnothing= & 80.371^{\circ} \text { co-latitude } \\
& \left(\text { geomagnetic latitude } 9.629^{\circ} \mathrm{N}\right) \\
\psi= & -6.582^{\circ} \\
\sin \psi= & -0.1146 \\
\cos \psi= & 0.9934 .
\end{aligned}
$$

If the angle $\alpha_{m}^{\prime}$ is known, a simpler cosine formula can be used

$$
\cos \psi=-\cos \left(\phi_{m}-\phi\right) \cos \alpha_{m}^{\prime}+\sin \left(\phi_{m}-\phi\right) \sin \alpha_{m}^{\prime} \cos \theta_{m} .
$$

The geomagnetic longitude $\alpha_{m}$ of Alibag is the angle measured eastward at the geomagnetic North Pole from the meridian passing through the geomagnetic North Pole and the geographic South Pole. We can use spherical trigonometry to find $\alpha_{m}^{\prime}$ as

$$
\alpha_{m}^{\prime}=\alpha_{m}-\pi=\alpha_{m}-180^{\circ} .
$$

The required geomagnetic longitude $\alpha_{m}$ is then given by

$$
\alpha_{m}=\pi+\alpha_{m}^{\prime}=180^{\circ}+\alpha_{m}^{\prime} .
$$




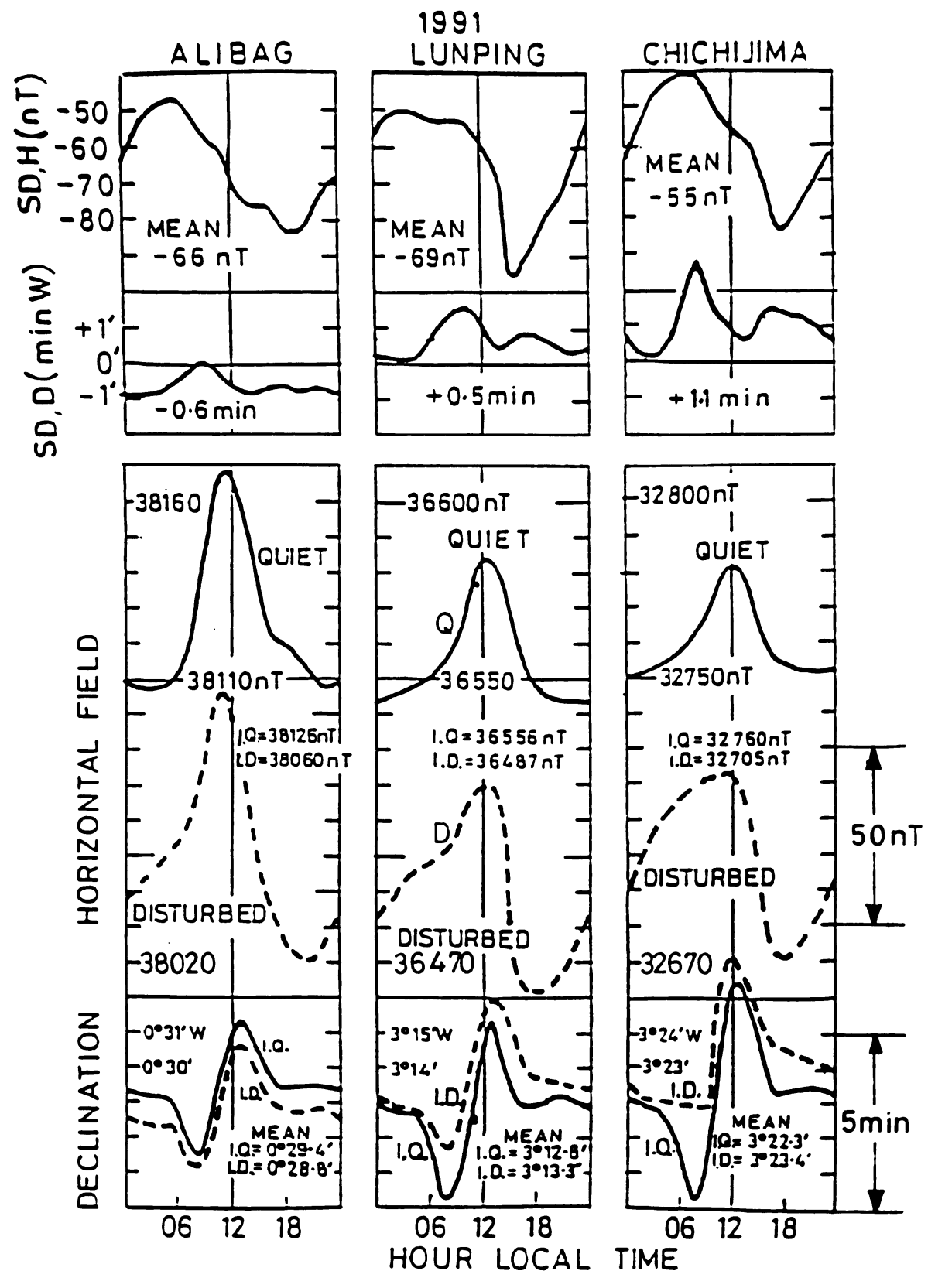

Fig. 2. The mean daily variations of horizontal filed $(H)$ and the declination $(D)$ for international quiet and disturbed days of the year 1991 and the daily disturbance variations at Alibag, Lunping and Chichijima.

From the sine and cosine rules of spherical trigonometry

$$
\begin{aligned}
\sin \alpha_{m}^{\prime} & =\frac{\sin \left(\phi_{m}-\phi\right) \sin \theta}{\sin \emptyset} \\
\cos \alpha_{m}^{\prime} & =-\cos \left(\phi_{m}-\phi\right) \cos \psi+\sin \left(\phi_{m}-\phi\right) \sin \psi \cos \theta
\end{aligned}
$$

where $\sin \alpha_{m}^{\prime}=-0.5684$ and $\cos \alpha_{m}^{\prime}=0.8228$ giving $\alpha_{m}^{\prime}=$ $-34.639^{\circ}$, and the geomagnetic longitude $\alpha_{m}=145.361^{\circ} \mathrm{E}$ in agreement with the value $145.6^{\circ} \mathrm{E}$ given in the yearbook.

The annual mean declination at Alibag for 1985 from the yearbook is

$$
D=-0.638^{\circ}
$$

Which compares with $-0.8^{\circ}$ given in the Table 1 . Therefore

$$
D^{\prime}=D-\psi=5.944^{\circ} \text {. }
$$

With a positive sign, compared with the result $\psi-D=$ $-6.4^{\circ}$.

The parameters $\psi, \psi-D$ and $\sin (\psi-D)$ for all stations are also given in Table 1.

\section{Disturbance Daily Variation of $\boldsymbol{H}$ and $\boldsymbol{D}$}

The disturbed day values of $H$ and $D$ at Kodaikanal were shown to be lower than the corresponding values on quiet days (Rastogi, 1991, 1992). The mean solar daily variations $(S q)$ of $H$ and $D$ for all IQ days and ID days of the year 1991 at Alibag, Lunping and Chichijima are shown in Fig. 2. The disturbance daily variation $(S D)$ of $H$ and $D$ are also presented in the figure. It is seen that for all stations, the value of $H$ field for any of the hours on ID days is lower than that on IQ days. The decrease averaged for all hours was 66 
$\mathrm{nT}$ at Alibag, $69 \mathrm{nT}$ at Lunping and $55 \mathrm{nT}$ at Chichijima. The disturbance daily variations $S D(H)$ showed a dawn maximum (magnitude of $S d-S q$ is minimum) and a dusk minimum as observed at other stations by Vestine et al. (1947) and Sugiura and Chapman (1960). This shows that the effect of disturbance on $H$ field is minimum during dusk and maximum during dawn.

The declination values for all hours of the day at Alibag were found to be lower on ID days than on IQ days with mean values of $0^{\circ} 29.4^{\prime}$ for IQ days and $0^{\circ} 28.8^{\prime}$ for ID days. On the other hand, declination at Lunping and Chichijima of any hours of the ID days were increased compared to those on IQ days. The mean $S D(D)$ was -0.6 min at Alibag, $+0.5 \mathrm{~min}$ at Lunping and $+1.1 \mathrm{~min}$ at Chichijima. The daily variation of $S D(D)$ showed a maximum in the forenoon hours at all stations. At Alibag, deviation is minimum at morning but for the other two stations deviation is maximum in the forenoon hours.

The daily variations of declination averaged over IQ days and ID days of the year 1959 for Alibag and Kakioka are shown in Fig. 3. The westerly declination at Alibag was lower on ID days than on IQ days for any hour of the day as shown in Fig. 2 for the year 1991. On the other hand, the westerly declination at Kakioka was higher on ID days than on IQ days for any of the hours of the day. The

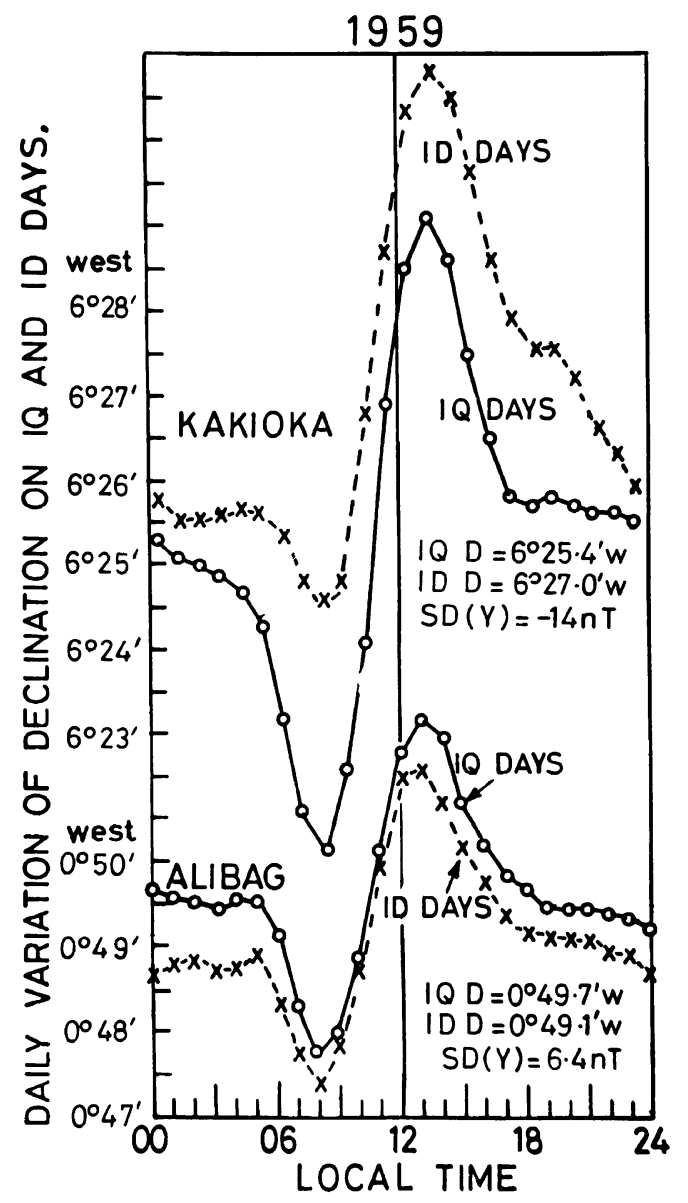

Fig. 3. The yearly mean daily variations of the westward field at Kakioka on the international quiet and disturbance days for the years 1957 to 1960. mean declination at Alibag was $0^{\circ} 49.7^{\prime} \mathrm{W}$ on IQ days and $0^{\circ} 49.1^{\prime} \mathrm{W}$ on ID days leading to $S D(Y)$ to be equal to 6.4 nT. For Kakioka, declination was $6^{\circ} 25.4^{\prime} \mathrm{W}$ on IQ days and $6^{\circ} 27.0^{\prime} \mathrm{W}$ on ID days leading to $S D(Y)$ to be equal to -14 $\mathrm{nT}$. The annual mean $S D(H)$ for 1959 was $-62 \mathrm{nT}$ at Alibag and $-53 \mathrm{nT}$ at Kakioka. Thus $\Delta Y / \Delta H$ was equal to -0.10 at Alibag and +0.26 at Kakioka. Referring to Table 1 , the value of $\sin (\psi-D)$ is -0.11 for Alibag and +0.22 for Kakioka. It is satisfactory to find that the values of $\Delta Y / \Delta H$ at the two stations are close to the corresponding values of

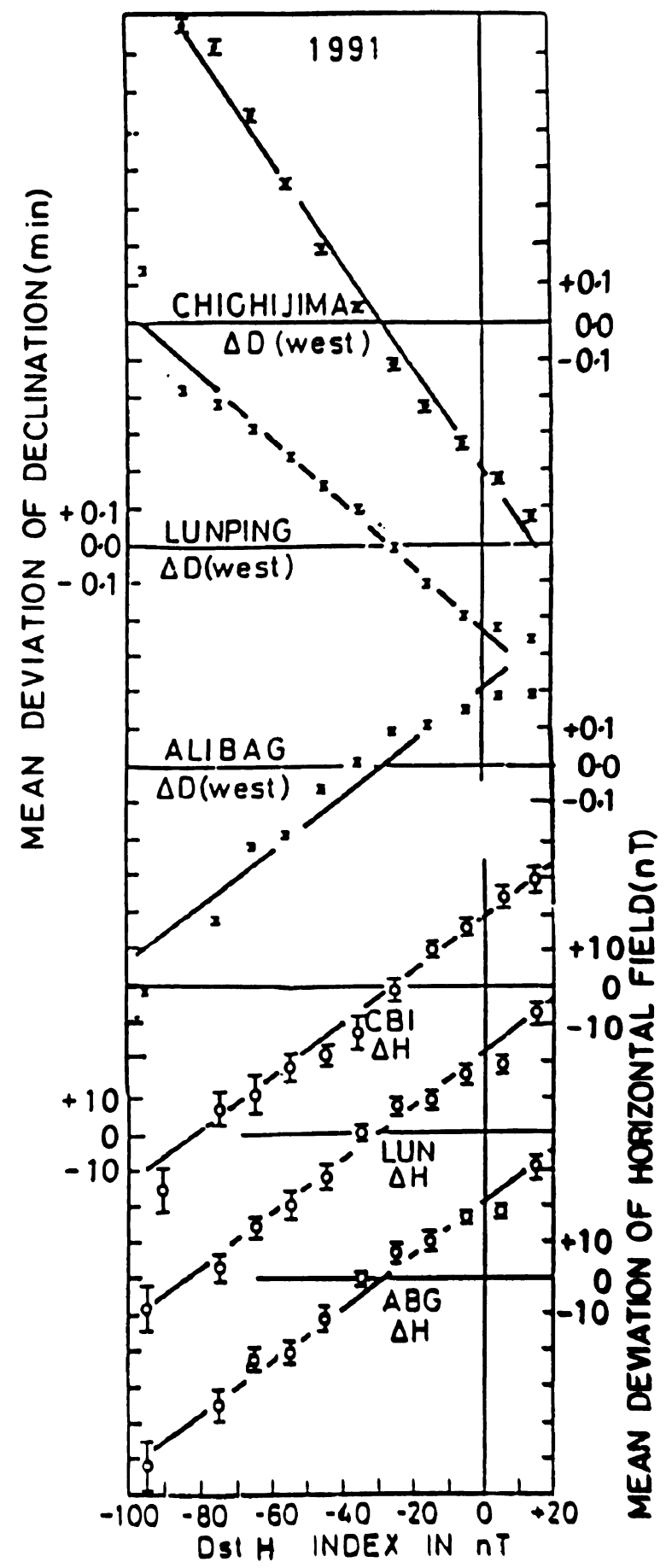

Fig. 4. The deviations of horizontal filed and declination in relation to Dst index at Alibag, Lunping and Chichijima for the year 1991. 


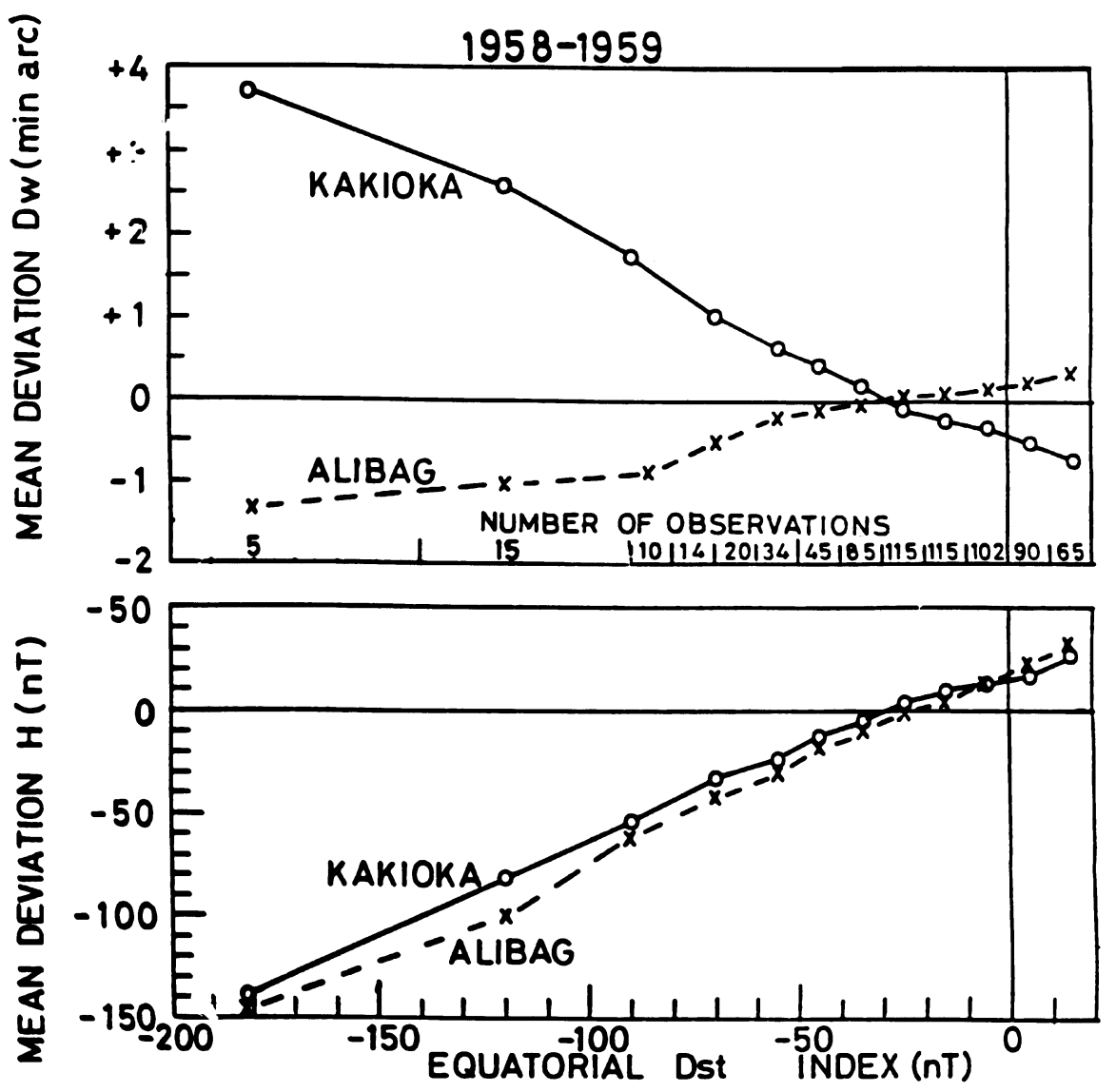

Fig. 5. The day-to-day changes of the daily mean deviations of horizontal field and declination in relation to the Dst index for the observatories Alibag and Kakioka during the IGY-IGC period (1958-1959).

$\sin (\psi-D)$.

Thus, it is seen that the westward declination at Alibag is decreased on disturbed days while the same is increased on disturbed days for Lunping, Chichijima and Kakioka. In other words, on disturbed days the magnetic vector is rotated clockwise at Alibag and anti-clockwise at Lunping, Chichijima and Kakioka.

\section{The $\Delta H$ and $\Delta Y$ in Relation to $D s t$ Index}

The daily means of $H$ and $D(w)$ at Alibag, Lunping and Chichijima in relation to the corresponding daily mean value of Dst index have been studied. The deviations $\Delta H$ and $\Delta D$ for each day were calculated by subtracting the monthly mean values from individual day values. These deviations were grouped based on daily $D s t$ index as +20 to $+10,+10$ to 0,0 to $-90 \cdots-90$ to -100 and the average $\Delta H$ and $\Delta D$ with standard errors were computed for each group. The relationship between the $\Delta H$ and $\Delta D$ at each station with the Dst index are shown in Fig. 4. As expected, the deviations of $\Delta H$ at all three stations decreased with decreasing value of Dst index, i.e. with increasing storminess. Further, the slopes of the regression line between $\Delta H$ and Dst index are nearly same.

The deviation of $D(w)$ decreased with decreasing values of $D s t$ at Alibag, i.e. eastward field increased with increasing magnitude of the equatorial ring current. At Lunping and Chichijima, the decreasing value Dst were associated with increasing value of $\Delta D$, i.e. the increase of the equatorial ring current caused a decrease of the eastward geomagnetic field. Here the slopes of regression lines between $\Delta D$ and $D s t$ index are not uniform. The ratio $\Delta Y / \Delta H$ at Alibag, Lunping and Chichijima were $-0.12,+0.13$ and +0.17 respectively. These values compare well with values of $\psi-D$ at these places as $-0.17,+0.17$ and 0.17 respectively. In Fig. 5 are shown the result of similar analysis of the daily mean values of $H$ and $D$ at Alibag and Kakioka for an extended period of 1958-1959, the years of maximum solar activity. The relationship between $\Delta H$ and $\operatorname{Dst}(H)$ were practically the same at Alibag and Kakioka. Regarding the declination, the mean $\Delta D$ at Alibag decreased with decreasing $D s t$ index whereas at Kakioka mean $\Delta D$ increased monotonously with decreasing $D s t$ index. For a decrease of $200 \mathrm{nT}$ of the $D s t$ index, $\Delta D$ decreased by $1.75 \mathrm{~min}$ $(19.4 \mathrm{nT})$ at Alibag and increased by $4.25 \mathrm{~min}(37.4 \mathrm{nT})$ at Kakioka. Thus $\Delta Y / \Delta H$ was -0.10 at Alibag and +0.19 at Kakioka compared to value of $\psi-D$ as -0.11 and 0.17 respectively.

\section{Storm Sudden Commencement (SSC) in $H$ and $D$}

Fukushima (1966) seems to be the first to study the amplitudes of the storm sudden commencement in declination. He introduced the idea of magnetic meridian at ground and magnetospheric levels and derived the disturbance vector 


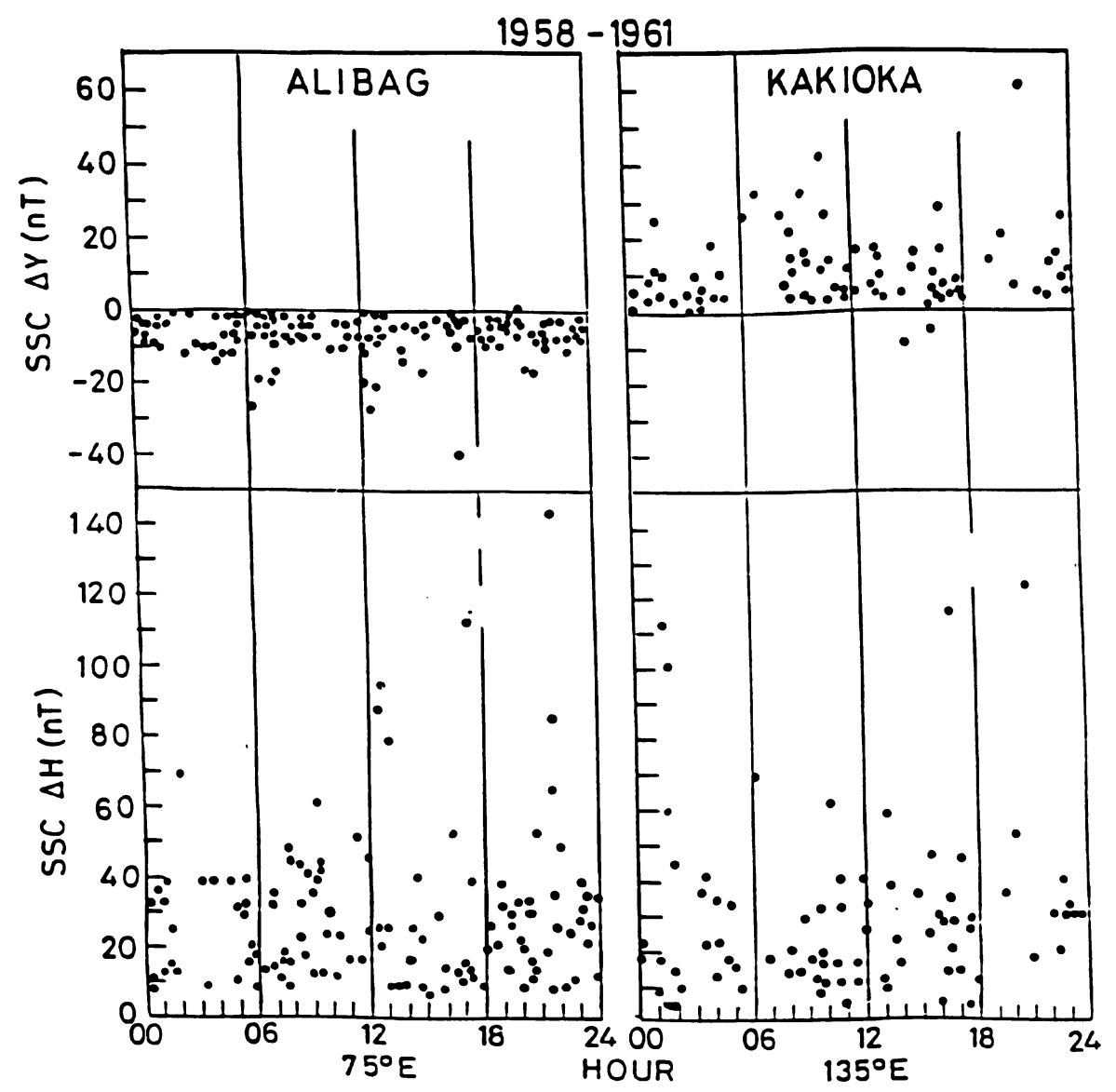

Fig. 6. Individual amplitudes of SSC in $H$ filed and declination versus local standard time at Alibag and Kakioka during the years $1958-1961$.

during SSC. Rastogi (1999b) has described a comprehensive study of the SSC impulses in $H, Y$ and $Z$ fields at Indian observatories. The SSC in $D$ at Alibag was shown to be westward for any time of the day or night.

The amplitudes of the individual SSCs in $H$ and $Y$ fields at Alibag and Kakioka against local time for the year 19581961 are plotted in Fig. 6. The SSC in $H$ at both the stations were comparable in magnitude. The amplitude of SSC in $Y$ component was all negative at Alibag but all positives at Kakioka. The sudden commencements are not due to the equatorial ring current but are due to the compression of the magnetosphere and due to the magnetopause electric field. Still the SSC disturbance vector at Alibag shows a westward tilt as $\Delta Y / \Delta H$ is negative, while at Kakioka it tilts eastward as $\Delta Y / \Delta H$ being positive. At both the stations, it is towards the magnetic dipole meridian.

\section{Storm-Time Variations of $\boldsymbol{H}$ and $\boldsymbol{Y}$ Fields}

One of the most important aspects of the geomagnetic storms is the storm-time variation of the geomagnetic field components, which are the results of the equatorial ring current as the primary source. Extensive studies have been made about storm-time variations of the $H$ field but the study of $Y$ field is still ignored. The conclusion by Sugiura and Chapman (1960) that the storms do not have any systematic variations of the declination field has probably discouraged scientists to take up the problem. Rastogi's (1992) result that the storm-time variations of $H$ and $D$ at Ko- daikanal and Alibag are remarkably similar to the corresponding storm-time variations of $H$ had rather surprised the scientists. The storm-time variations of $H$ and $D$ fields at Alibag, Lunping and Chichijima during the storm commencing at 1635 UT on 8 July 1991 have been investigated here and are shown in Fig. 7. The SSC was followed by a strong main phase increase of Dst between 17 and 20 UT on 8 July 1991. The main phase started at about 06 UT on 9 July 1991 and $\operatorname{Dst}(H)$ index reached it minimum value of $-200 \mathrm{nT}$ at $14 \mathrm{UT}$ on 9 July 1991 . The storm-time variations of $H$ at Alibag, Lunping and Chichijima were very similar to each other and followed the $\operatorname{Dst}(H)$ index variation. The westerly declination at Alibag showed a sharp decrease during the main phase of the storm on 9 July. But the declination (westerly) at Lunping and Chichijima showed an increase on 9 July although not synchronous with the variations of the Dst $(H)$ index. The significant decrease of declination at all stations around 2030 UT on 8 July before the start of the main phase remains to be explained.

The storm-time variations of $H$ and $Y$ fields at Alibag and Kakioka during three large storms during the IGY-IGC period, starting at 0126 UT on 11 February 1958, starting at 0748 UT on 8 July 1958 and at 0803 UT on 15 July 1959 are shown in Fig. 8. The storm of 11 February 1958 had its peak intensity around 1200 UT with Dst index reaching below $-400 \mathrm{nT}$. It is seen that $\operatorname{Dst}(H)$ at Alibag and Kakioka as well as $\operatorname{Dst}(Y)$ at Kakioka were remarkably similar showing a peak decrease of $Y$ at Kakioka below 

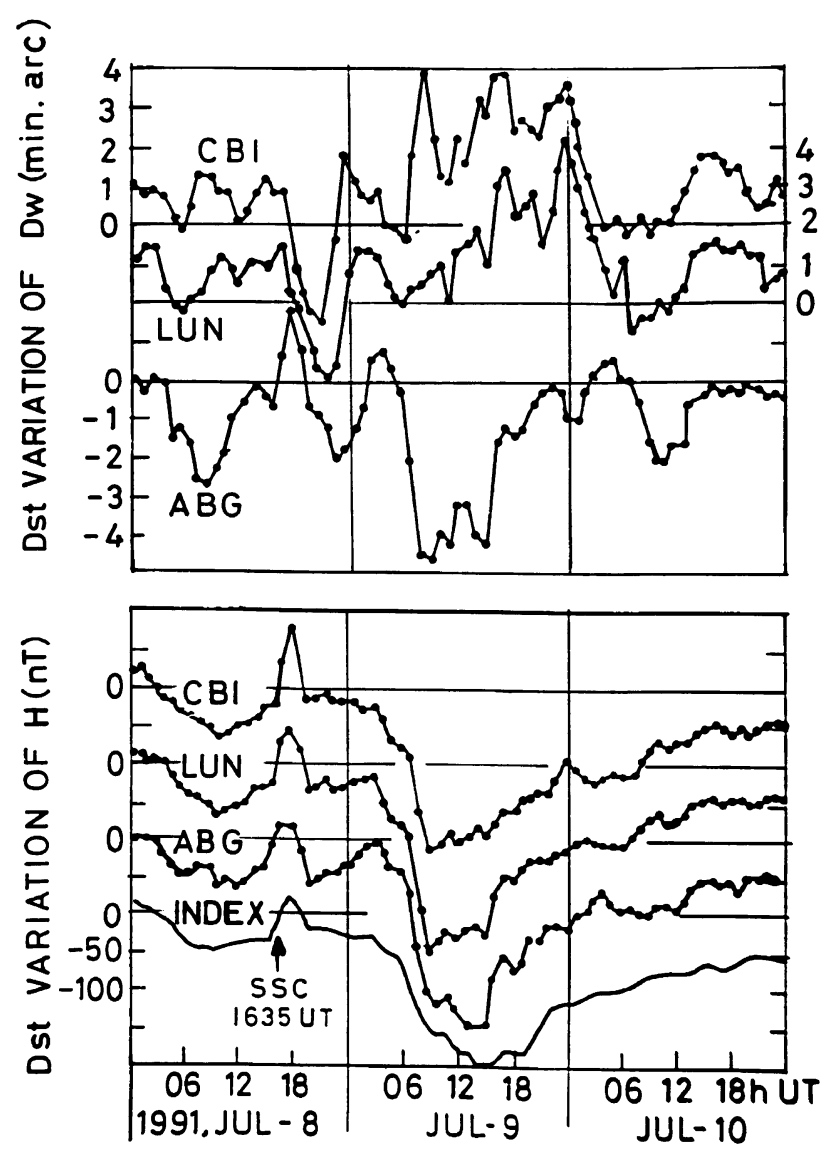

Fig. 7. Storm-time variations of $H$ field and declination at Alibag, Lunping and Chichijima compared with corresponding variations of Dst index.

$-100 \mathrm{nT}$. But $\operatorname{Dst}(Y)$ at Alibag was positive during the main as well as recovery phase of the storm. The storm of 8 July 1958 too was classified as strong with $\operatorname{Dst}(H)$ index decreases to $-300 \mathrm{nT}$. In this case too the $\operatorname{Dst}(Y)$ at Kakioka was very similar to $\operatorname{Dst}(H)$ at Alibag and Kakioka and all these three were remarkably similar to the Dst index. On the other hand, the $\operatorname{Dst}(Y)$ at Alibag showed positive values during the main phase of the storm. Exactly the same features were seen during the storm of 15 July 1959 where also $\operatorname{Dst}(Y)$ at Alibag was opposite to that at Kakioka.

The ground magnetic field may often be affected by the overhead ionospheric currents driven by the electric fields imposed at the auroral region. This is important especially during transient and short period changes of the magnetic field, like those during the SSC and during the main phase when the disturbance ring current is just being energized. The sign of SSC in $Y$ field do follow the direction of geomagnetic dipole meridian with respect to the ground magnetic meridian but the ratio of $\Delta Y / \Delta H$ at the time of SSC does not necessarily follow the value of $\sin (\psi-D)$ at the station. Occasional swing of $\Delta Y$ after SSC and before the onset of main phase may be the effect of overhead ionospheric current. This aspect needs a separate study in correlation with simultaneous variations of $\mathrm{AE}$ index, solar wind parameters and IMF Bz field.

It may be concluded that there is a significant variation of the declination (or eastward field) at low latitudes associated

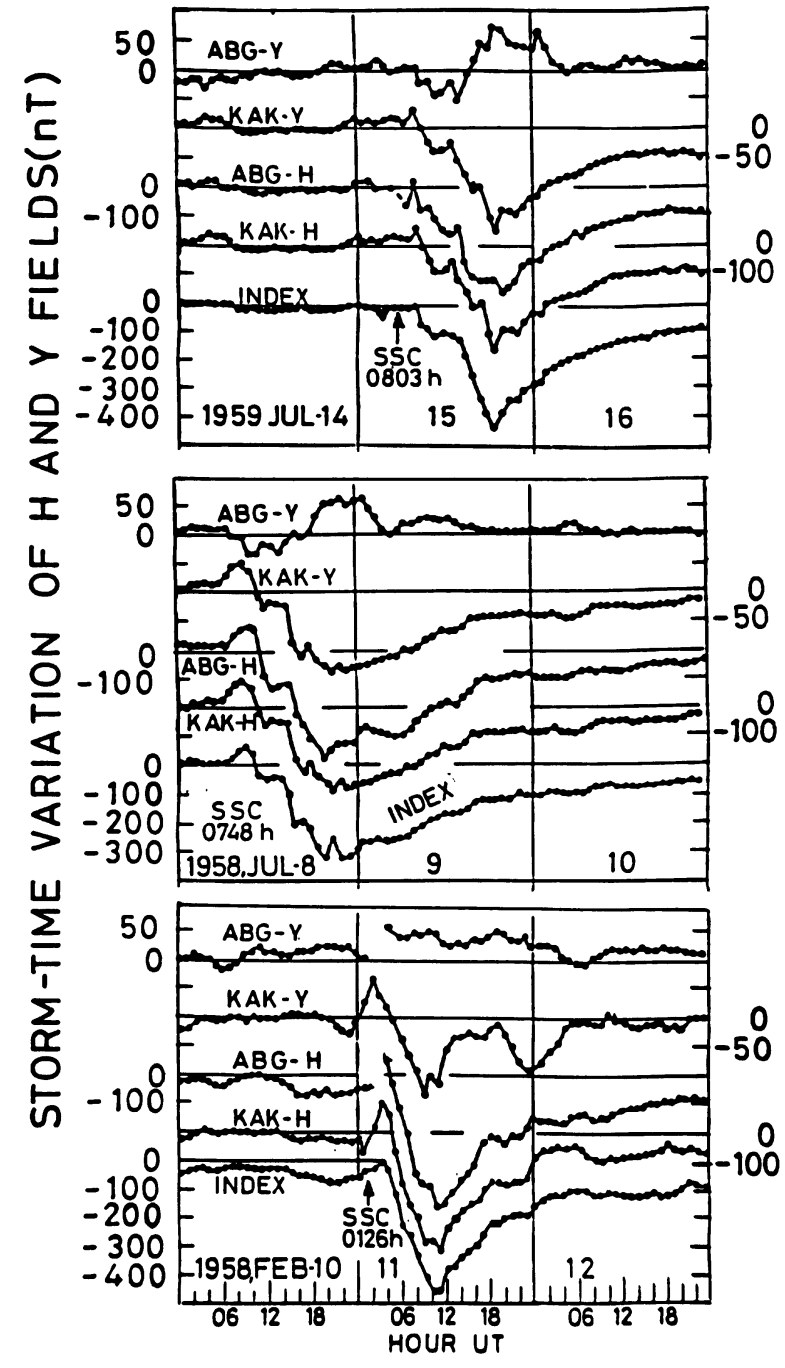

Fig. 8. Storm-time variations of $H$ field and $Y$ field at Kakioka and Alibag compared with the corresponding variations of the Dst index.

with geomagnetic storms. The equatorial ring current produces a decrease of $H$ field at all stations but it produces different effect on $Y$ field depending on the geomagnetic longitude of the station. At stations west of $180^{\circ}$ geomagnetic longitudes, an increase of the eastward field is observed with the main phase of storm, while at stations east of $180^{\circ}$ geomagnetic longitudes, there is a decrease of the eastward field.

\section{Disturbance Effect on $H$ and $D$ at Indo-USSR Chain of Stations}

Since 1975, there exists a very good latitudinal chain of geomagnetic observatories along $145^{\circ} \mathrm{E}$ geomagnetic longitude sector in India and former USSR states. These observatories spread from the magnetic equator (Trivandrum) to near $60^{\circ} \mathrm{N}$ dip latitude (Novosibirsk). The declination varied from $3^{\circ} \mathrm{W}$ at low latitudes to $0^{\circ}$ near $S q$ focus and $9^{\circ} \mathrm{E}$ at high latitudes. These stations and their coordinates are listed in Table 1.

Rastogi (1996b) studied the relationship between the geomagnetic activity and the daily means of $H$ and $D$ fields at 12 stations along the Indo-Russian longitude sector and 


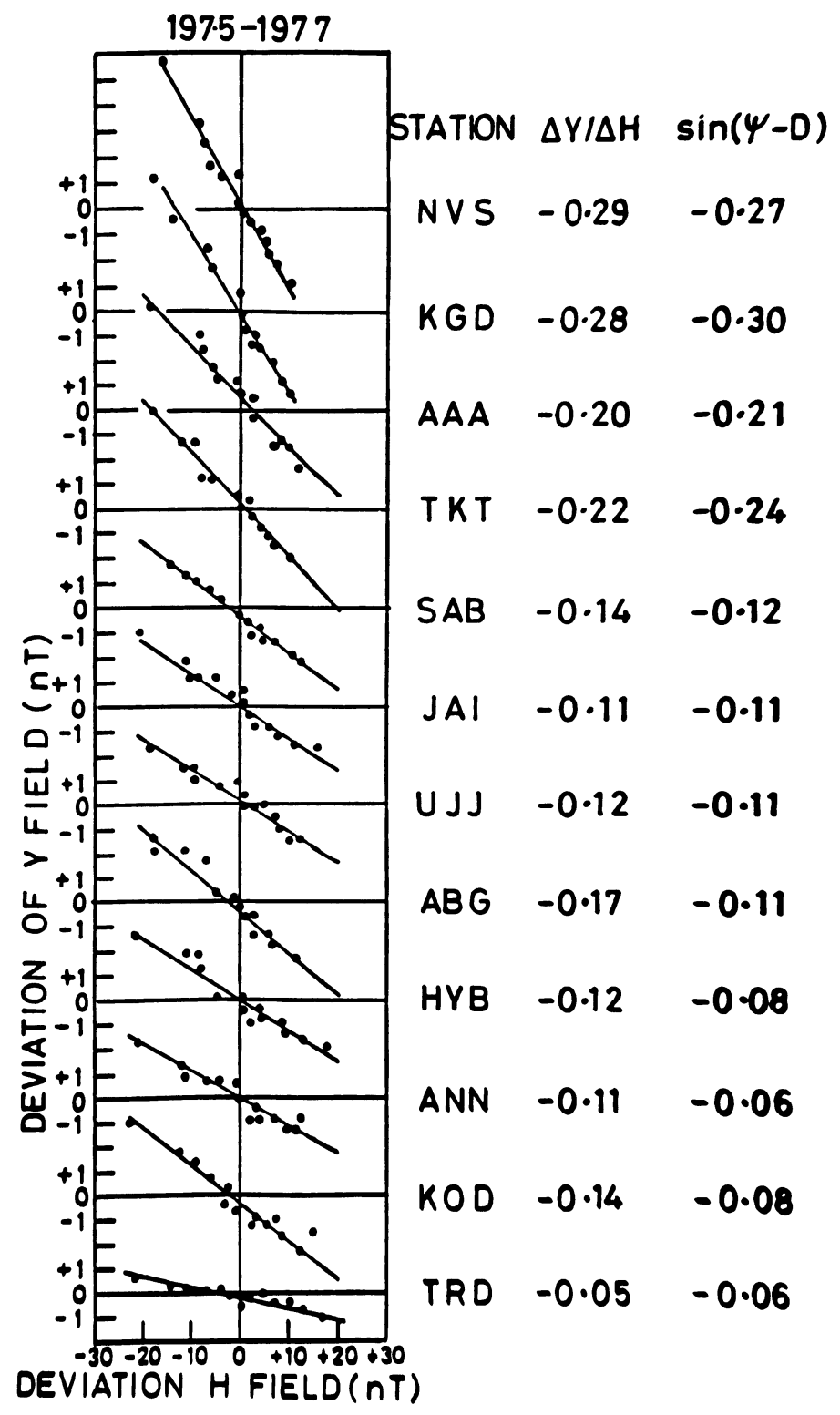

Fig. 9. Relationship between the daily means of $H$ and $Y$ fields at different stations along Indo-Russian longitude sector during $1975-1977$.

found that at all stations the daily mean of $\Delta H$ decreased with increasing magnetic character figure $C_{p}$. The slope of the regression line of $\Delta H$ versus $C_{p}$ varied as the cosine of the geomagnetic latitude $\left(\lambda_{m}\right)$ of the station. On the other hand, $\Delta Y$ was found to increase with increasing magnetic character figure $C_{p}$. The slope of the regression line of $\Delta Y$ verses $C_{p}$ increased as secant of the geomagnetic latitude $\left(\lambda_{m}\right)$ of the station. Using $\Delta H$ and $\Delta Y$ values for the same $C_{p}$ group, the relationship of $\Delta Y$ verses $\Delta H$ at each of the stations in the chain have been reconstructed in Fig. 9. It is seen that $\Delta Y / H$ varied from a value of -0.05 at the equatorial station to -0.29 at high latitude station Novosobirisk.

\section{Conclusion}

The disturbance ring current on the average is shown to be aligned perpendicular to the dipole meridian instead of ground magnetic meridian. The direction of the disturbance vector is indicated by $\sin (\psi-D)$ where $\psi$ and $D$ are dipole and ground declinations at the observatory. The effect of magnetic disturbances on $H$ field is similar at all stations but there is a longitudinal dependence on $Y$ field.

Acknowledgments. Thanks are due to the University of Sydney, Australia for the visiting professorship to one of the authors (R. G. Rastogi) where the work was started. Thanks are also due to Gujarat University, Ahmedabad, India and Physical Research Laboratory, Ahmedabad, India for facilities provided to the authors.

\section{References}

Akasofu, S. I. and S. Chapman, The ring current, geomagnetic disturbance and the Van Allen radiation belts, J. Geophys. Res., 66, 1321-1350, 1961.

Chapman, S., An outline of theory of magnetic storms, Proc. Roy. Soc. Lond., A95, 1918.

Chapman, S. and V. C. A. Ferraro, A new theory of magnetic storms Part I The initial phase, Terr. Mag. Atmos. Elect., 36, 77-97, 1931a. Part II The initial phase, Terr. Mag. Atmos. Elect., 36, 171-186, 1931b. Part III The initial phase, Terr. Mag. Atmos. Elect., 37, 147-156, 1932a. Part IV The initial phase, Terr. Mag. Atmos. Elect., 37, 421-429, 1932 b. 
Fukushima, N., Declination change of SC, its local time and seasonal dependence at Kakioka, Japan, J. Geomag. Geoelectr., 18, 99-101, 1966.

Iyemori, T., Storm-time magnetospheric currents inferred from mid-latitude geomagnetic field variations, J. Geomag. Geoelectr., 42, 12491265,1990 .

Moos, N. A. F., Magnetic observations made at the government observatory, Bombay 1846 to 1905 and their discussions, Part II, The phenomenon and its discussion, Bombay, 1910.

Obayashi, T. and J. A. Jacobs, Sudden commencement of magnetic storms and atmospheric dynamo action, J. Geophys. Res., 62, 589-616, 1957.

Rastogi, R. G., Field aligned currents at equatorial latitudes during geomagnetic disturbances, Ind. J. Radio Space Phys., 20, 319-326, 1991.

Rastogi, R. G., Geomagnetic disturbance effects on equatorial electrojet current, J. Geomag. Geoelectr., 41, 317-324, 1992.

Rastogi, R. G., Remarkable solar cycle and seasonal dependence of the diurnal geomagnetic $D$-variation of equatorial electrojet station Kodaikanal, J. Geomag. Geoelectr., 45, 657-668, 1993a.

Rastogi, R. G., Meridional currents during equatorial geomagnetic disturbances, Geophys. Res. Lett., 20, 5-7, 1993b.

Rastogi, R. G., Solar flare effects on zonal and meridional currents at equatorial electrojet station Annamalainagar, J. Atmos. Terr. Phys., 58, 1417-1420, 1996a.

Rastogi, R. G., A new relationship between the geomagnetic $\mathrm{H}$ and $\mathrm{Y}$ fields during disturbed conditions, Ind. J. Radio Space Phys., 25, 300-307, $1996 \mathrm{~b}$.

Rastogi, R. G., Meridional equatorial electrojet currents in the American sector, Annals Geophysicae, 17, 220-230, 1999a.

Rastogi, R. G., Signatures of storm sudden commencements in geomagnetic H, Y and Z fields at Indian observatories during 1958-1992, Annals Geophysicae, 17, 1426-1438, 1999b.
Rastogi, R. G., B. M. Pathan, D. R. K. Rao, T. S. Sastry, and J. H. Sastri, Solar flare effects on the geomagnetic elements during normal and counter electrojet periods, Earth Planets Space, 51, 947-957, 1999.

Sano, Y., Morphological studies on sudden commencement of magnetic storms using the rapid run magnetograms during the IGY, Mem. Kakioka Magnetic Observatory, 11(1), 1-52, 1963.

Schmidt, A., Erdmagnetismus, Enzyk, Math. Wiss., 6, Leipzig, 1917.

Singer, S. F., A new model of magnetic storms and auroras, EOS Trans. Amer. Geophys. Union, 38, 175-190, 1957.

Sugiura, M., Hourly values of equatorial Dst for IGY in Ann. Inter. Geophys. Year, 35, 9-45, Pergamon Press, Oxford, 1964.

Sugiura, M. and S. Chapman, The average morphology of geomagnetic storm with sudden commencement, Abhandl. Akad. Wiss. Gottingen. Math-Physik. K.I. Sonderh, 4, 53 pp, 1960.

Tsunomura, S., Characteristics of geomagnetic sudden commencement observed in middle and low latitudes, Earth Planets Space, 50, 755-772, 1998.

Tsunomura, S., T. Toya, Y. Ishii, and S. Teshima, A study of geomagnetic storms on the basis of magnetic observations in Japanese chain observatories, Mem. Kakioka Magnetic Observatory, 27, 1-105, 1999.

Vestine, E. H., L. Laporte, I. Langiand, and W. E. Scott, The geomagnetic field and its application and analysis, Carnegie Institute of Washington, Pub. No. 580, 1947.

Wilson, C. R. and M. Sugiura, Hydromagnetic interpretation of sudden commencement of magnetic storms, J. Geophys. Res., 66, 4097-4111, 1961 .

R. G. Rastogi (e-mail: parvs@prl.ernet.in), D. E. Winch, and M. E. James 